\title{
Mundo do trabalho, políticas educacionais e o direito à educação: \\ o Ensino Médio Integrado nos Institutos Federais
}

\author{
World of labor, educational policies and the right to education: \\ Integrated High School in Federal Institutes

\section{El mundo del trabajo, políticas educativas y el derecho a la educación: \\ Escuela Secundaria Integrada en Institutos Federales}

\author{
SIMONE APARECIDA MILLIORIN \\ Instituto Federal do Paraná, Campo Largo- PR, Brasil. \\ MONICA RIBEIRO DA SILVA* \\ Universidade Federal do Paraná, Curitiba- PR, Brasil.
}

\begin{abstract}
RESUMO: O artigo investiga a atuação dos institutos federais e do ensino médio integrado como política educacional em favor da ampliação do direito à educação. Foram analisados dados do Censo Escolar e do Relatório de Taxas de Rendimento dos campi que compõem os 38 institutos federais na série histórica de 2007 a 2017. Os resultados atestam a expansão e a interiorização, o aumento da oferta e o atendimento de populações antes não atendidas como fatores determinantes da democratização e efetivação do direito à educação. Nas considerações finais se problematiza esse cenário diante da atual reforma.

Palavras-chave: Política educacional. Direito à educação. Ensino médio integrado. Institutos federais.
\end{abstract}

\footnotetext{
* Graduada em Pedagogia e mestra em Educação pela Universidade Federal do Paraná, mesma instituição na qual é doutoranda em Educação. Atuou como professora e pedagoga em escolas da Rede Municipal de Educação de Campo Largo. Atualmente é pedagoga no Instituto Federal do Paraná. E-mail:<simonemilliorin@yahoo.com>.

* Mestra em Educação pela Universidade Federal de São Carlos e doutora em Educação pela Pontifícia Universidade Católica de São Paulo. É professora na Universidade Federal do Paraná e coordena o Grupo de Pesquisa Observatório do Ensino Médio e a Rede Nacional de Grupos de Pesquisa sobre Ensino Médio (Empesquisa). E-mail: <monicars03@gmail.com>.
} 
ABSTRACT: The article investigates the role of federal institutes and integrated high school as an educational policy in favor of expanding the right to education. Data from the Censo Escolar and the Relatório de Taxas de Rendimento of the campuses that make up the 38 federal institutes in the historical series from 2007 to 2017 were analyzed. The results attest to the expansion and interiorization, the increase in supply, and the assistance of previously non-assisted populations as determinants of democratization and realization of the right to education. In the final remarks, this scenario is problematized in the face of the current reform.

Keywords: Educational policy. Right to education. Integrated high school. Federal institutes.

RESUMEN: El artículo investiga la acción de los institutos federales y la secundaria integrada como política educativa a favor de la ampliación del derecho a la educación. Se analizaron los datos del Censo Escolar y del Reporte de Tasa de Ingresos de los campus que integran los 38 institutos federales en la serie histórica de 2007 a 2017. Los resultados demuestran la expansión e interiorización, el aumento de la oferta y el servicio a poblaciones previamente no atendidas como determinantes de la democratización y la realización del derecho a la educación. En las observaciones finales, este escenario se problematiza frente a la reforma actual.

Palabras clave: Política educativa. Derecho a la educación. Educación secundaria integrada. Institutos federales.

\section{Introdução}

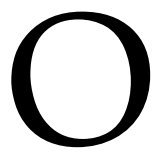

direito à educação se constituiu historicamente como condição de se conquistar outros direitos. Por meio da educação as pessoas adquirem conhecimentos que lhes dão as condições de se desenvolver cognitiva, social e culturalmente. Para além do plano individual, o acesso ao conhecimento, por meio da educação escolar, permite a formação, de modo a possibilitar uma participação autônoma, consciente, crítica e criativa da vida em sociedade. $\mathrm{O}$ acesso à escola é condição indispensável para o enfrentamento das desigualdades que permeiam as sociedades e, por isso, não pode ser um direito reservado a estrato social específico. Aí reside a necessidade de declará-la como direito de todas as pessoas e uma obrigação, um dever, do Estado. 
No caso brasileiro, com uma realidade marcada pelo elitismo e profundas desigualdades sociais, os direitos sociais, entre eles a educação, foram historicamente limitados a uma categoria de privilégios para poucos. Apesar de garantida a gratuidade do ensino primário desde o período imperial e posteriores conquistas na declaração da obrigatoriedade, do direito ao acesso e do dever do Estado em garantir a educação, são frágeis os instrumentos legais que possibilitam a responsabilização do Estado diante do acesso não universalizado.

A ampliação do acesso à escola no Brasil atendeu ao princípio de igualdade de oportunidades, sem assegurar a permanência e o prosseguimento nos estudos. O direito diferenciava-se entre os filhos das camadas mais pobres da população em que a frequência era de poucos anos e os poucos privilegiados que permaneciam por mais tempo. Dessa forma, a ampliação do direito precisava progredir no sentido de considerar as diferenças e desigualdades na sociedade.

O direito à educação coloca-se, ainda, como um grande desafio. Os avanços legais tardaram e precisam traduzir-se em políticas que garantam o acesso, a permanência, a efetiva aprendizagem e a conclusão, num horizonte de avanço democrático e de justiça social. É com a intenção de analisar esse contexto, na particularidade da última etapa da educação básica, que a pesquisa da qual resulta o presente artigo se debruçou. Trata, especialmente, da oferta do ensino médio integrado como alternativa para a atribuição de sentido e como forma de superação da histórica dualidade que vem caracterizando essa etapa educacional. O texto prioriza a análise dos institutos federais, relatando o processo de expansão e interiorização de suas unidades bem como das matrículas em cursos de ensino médio integrado realizadas nestas instituições, considerando o perfil dos estudantes que neles ingressaram e as médias percentuais de aprovação, reprovação e abandono. A pesquisa procurou, em síntese, dimensionar em que medida essa instituição vem contribuindo para a ampliação do direito à educação.

\section{Ensino Médio Integrado: sentido e finalidade da última etapa da educação básica}

Diante dos diversos desafios postos para que a educação básica se efetive como direito no Brasil, o ensino médio tem se apresentado como etapa vulnerável às condições internas e externas à escola para que os jovens permaneçam na escola, à elaboração de políticas públicas, aos interesses que permeiam a atribuição de sentido para a escola de nível médio.

O texto constitucional de 1988 representou um avanço legal na medida em que declarou o acesso à escola obrigatória e gratuita como direito público subjetivo, o que permite o constrangimento do Estado, pelo cidadão, diante da não oferta de vaga e a consequente responsabilização da autoridade competente em caso de descumprimento. Em 1996, a Lei 
de Diretrizes e Bases (LDB) também sinalizou com a ampliação do direito ao considerar como educação básica a educação infantil, o ensino fundamental e o ensino médio. Na década seguinte, a Emenda Constitucional nº 59/2009 determinou que a escolaridade obrigatória compreende a faixa etária dos quatro aos dezessete anos. Esses avanços, porém, limitam-se ao acesso à vaga e maior tempo de obrigatoriedade de permanência, sem impacto efetivo na garantia da aprendizagem. Além disso, a obrigatoriedade na educação infantil ainda precisa ser ampliada, incluindo crianças de 0 a 3 anos, bem como ainda é preciso garantir, legalmente, a obrigatoriedade do ensino médio.

O Plano Nacional da Educação (PNE) 2014-2024 aprovado pela Lei nº 13.005/2014 impulsionou para mudanças neste quadro que têm sido, porém, timidamente atendidas. Em sua Meta 3 o PNE estabeleceu a universalização, até o ano de 2016, do atendimento escolar para a população de 15 a 17 anos, o que não foi alcançado. Ao final desse período totalizavam aproximadamente 1.5000.000 jovens sem qualquer vínculo escolar (SILVA, 2020). De acordo com o Relatório do $3^{\circ}$ Ciclo de Monitoramento do Plano Nacional de Educação (INEP, 2020), em 2019 "cerca de 1,9 milhão de jovens de 15 a 17 anos que frequentam a escola ainda estão matriculados no ensino fundamental" (p. 14). Nesse mesmo ano, somavam $73,1 \%$ o percentual de pessoas entre 15 e 17 anos matriculadas no ensino médio ou com a educação básica concluída (INEP, 2020, p. 90). Se atentarmos para a última década, verifica-se um crescimento expressivo da inclusão educacional dessa faixa etária da ordem de 10,2 p.p. entre 2012 e 2019 (INEP, 2020, p. 90), mas distante, ainda, da universalização proclamada no Plano Nacional de Educação, que traçou o objetivo de incluir $85 \%$ das pessoas de 15 a 17 anos no ensino médio até 2024. Some-se a esse cenário as expressivas desigualdades regionais e sociais, características históricas do sistema escolar brasileiro.

Além da ampliação do acesso e justamente devido a ela, se vê colocada a pergunta quanto às formas de oferta e suas bases curriculares. Na direção de encontrar uma resposta é que se insere a proposta de ensino médio integrado (EMI).

O EMI está ancorado em uma perspectiva que advoga a formação integral dos sujeitos:

\footnotetext{
Trata-se de superar a redução da preparação para o trabalho ao se aspecto operacional, simplificado, escoimado dos conhecimentos que estão na sua gênese científico-tecnológica e na sua apropriação histórico-social. Como formação humana, o que se busca é garantir ao adolescente, ao jovem e ao adulto trabalhador o direito a uma formação completa para a leitura do mundo e para a atuação como cidadão pertencente a um país, integrado dignamente à sua sociedade política (CIAVATTA, 2008, p. 82).
}

O conceito de escola unitária anunciada por Antonio Gramsci (2001) contribuiu decisivamente para a definição dessa concepção de educação e a vincula ao mundo do trabalho. Para o autor, a escola deve adequar a capacidade de trabalhar técnica e 
intelectualmente de forma que a formação cultural inicial, de nível elementar e médio, possa proporcionar a aquisição dos instrumentos necessários à apropriação da cultura.

Moura, Lima Filho e Silva (2015) atentam para o fato de que, para Gramsci, a profissionalização aconteceria somente após o que equivaleria ao Ensino Médio brasileiro, pois até esta fase a formação deveria ser de cultura geral. No entanto, assim como Marx e Engels, Gramsci vislumbra a escola unitária numa sociedade onde as desigualdades sociais estejam superadas, pois as condições econômicas não favorecem a efetivação dessa concepção de escola, fazendo com que a profissionalização se torne uma necessidade para os jovens que necessitam trabalhar precocemente.

A perspectiva de formação unitária incorporada à concepção do EMI indica que não se trata de promover a justaposição de domínio de diferentes técnicas, mas de uma formação que conduza à apropriação dos princípios científicos, técnicos e tecnológicos dos modos como se organiza a produção da vida material e imaterial, contrapondo-se esse perfil de formação ao treinamento para uma tarefa ou função. A relação intrínseca entre formação científica básica e formação técnica e tecnológica é o que dá fundamento ao ensino médio integrado e sinaliza para contornos menos fragmentados e hierarquizados dos conhecimentos escolares.

No entanto, é preciso que tal perspectiva seja considerada dentro das condições postas. Assim, uma vez que a realidade brasileira antecipa essa formação profissional como condição de inserção mais qualificada dos jovens no mundo do trabalho, Moura, Lima Filho e Silva (2015) apontam o ensino médio integrado como possibilidade de manter certa coerência com a proposta de formação unitária.

\section{Os institutos federais na ampliação do direito à educação básica}

A criação dos institutos federais de educação, ciência e tecnologia (IF) em 2008 representa novo dinamismo para a educação profissional no Brasil. Fazendo parte do projeto de expansão da Rede Federal, os IF surgem como proposta de educação profissional comprometida com a melhoria na qualidade de vida das pessoas e articulada com o fator econômico, objetivando o desenvolvimento local e regional.

\footnotetext{
O papel que está previsto para os Institutos Federais é garantir a perenidade das ações que visem a incorporar, antes de tudo, setores sociais que historicamente foram alijados dos processos de desenvolvimento e modernização do Brasil, o que legitima e justifica a importância de sua natureza pública e afirma uma educação profissional e tecnológica como instrumento realmente vigoroso na construção e resgate da cidadania e da transformação social (BRASIL, 2010, p. 21).
}

A proposta político-pedagógica dos IF induz a uma prática educativa que pretende superar a separação entre formação técnica em sentido estrito e formação científica, oferecer uma educação inclusiva e uma formação humana integral. Tal formação abrange 
um sentido amplo para o mundo do trabalho, englobando todo o contexto que envolve a experiência humana, enquanto constitui-se como tal. Por isso, assume o trabalho, a tecnologia, a ciência e a cultura como eixos estruturantes do trabalho educativo por meio do ensino, da pesquisa e da extensão.

Entende-se que essa formação do trabalhador seja capaz de tornar esse cidadão um agente político, para compreender a realidade e ser capaz de ultrapassar os obstáculos que ela apresenta; de pensar e agir na perspectiva de possibilitar as transformações políticas, econômicas, culturais e sociais imprescindíveis para a construção de outro mundo possível. A referência fundamental para a educação profissional e tecnológica é o homem, daí compreender-se que a educação profissional e tecnológica dá-se no decorrer da vida humana, por meio das experiências e conhecimentos, ao longo das relações sociais e produtivas. A educação para o trabalho nessa perspectiva entende-se como potencializadora do ser humano, enquanto integralidade, no desenvolvimento de sua capacidade de gerar conhecimentos a partir de uma prática interativa com a realidade, na perspectiva de sua emancipação. Na extensão desse preceito, trata-se de uma educação voltada para a construção de uma sociedade mais democrática, inclusiva e equilibrada social e ambientalmente (BRASIL, 2010, p. 33-34).

A verticalização é um aspecto diferenciador desta instituição. A Lei nº 11.892/2008, que criou os IF, determina que cada instituto deverá garantir no mínimo 50\% (cinquenta por cento) das vagas à educação profissional técnica de nível médio, prioritariamente na forma integrada, 20\% (vinte por cento) a cursos de licenciatura, além de programas de formação pedagógica para professores da educação básica. O restante das vagas, isto é, 30\% (trinta por cento), seriam destinadas a cursos superiores de tecnologia, de bacharelado e engenharia, cursos de pós-graduação lato sensu e stricto sensu e cursos de formação inicial e continuada de trabalhadores nas áreas da educação profissional e tecnológica. Os IF devem atender ainda ao Decreto n⿳0 5.840, de 13 de julho de 2006, destinando, no mínimo, $10 \%$ do total de vagas de ingresso ao Programa Nacional de Integração da Educação Profissional à Educação Básica na Modalidade de Educação de Jovens e Adultos (Proeja). Tal verticalização possibilita aos estudantes formação em diferentes níveis e modalidades de ensino numa mesma instituição, além do diálogo entre as diferentes formações, estabelecendo um rico espaço de compartilhamento de saberes.

Os IF contam, em geral, com estrutura física adequada e com a atuação de docentes com formação em mestrado e doutorado, favorecendo a base científica para um ensino integrado e de qualidade. Com dedicação exclusiva, esses docentes atuam no ensino, na pesquisa e na extensão, além de atender de forma mais individualizada os estudantes no contraturno. Para tornar coerente a missão democrática e inclusiva da instituição há reserva de cotas para ingresso nos IF, assim como programas de assistência estudantil que visam a assegurar a permanência e o êxito dos estudantes em situação de vulnerabilidade socioeconômica. 
Tanto a concepção quanto as condições dadas favorecem uma atuação qualificada na democratização do acesso à educação básica uma vez que os IF promoveram a capilarização e interiorização da Rede Federal. No entanto, é preciso considerar que os IF estão inseridos numa sociedade e que o mercado exerce grande influência sobre as pessoas, comunidades e governos. Isso resulta em ambiguidades que vão se apresentando na implementação dos campi, na alternância de governos, na prática pedagógica e que refletem as disputas ideológicas, políticas e econômicas presentes na sociedade.

Neste sentido, se por um lado, existem condições favoráveis para que os IF contribuam na democratização do acesso à educação básica por meio da oferta do ensino médio integrado, de outro, é preciso analisar em que medida isso se deu em uma década de existência desse modelo de instituição que oferta educação profissional. Este, o objetivo central da presente pesquisa. Para alcança-lo, se procedeu à análise do acesso aos cursos de ensino médio integrado no processo de expansão e interiorização dos IF, considerando a série histórica de 2007 a 2017. Analisou-se, ainda, o perfil dos estudantes, levando em conta o sexo, raça/cor e faixa etária. Também foram analisados os dados sobre aprovação, reprovação e abandono no ensino médio integrado.

Do ponto de vista metodológico, a pesquisa se desenvolveu a partir dos bancos de dados de escolas e matrículas que constam no Censo Escolar divulgados pelo Instituto Nacional de Estudos e Pesquisas Anísio Teixeira (Inep). Foi possível identificar todos os campi, inclusive aqueles que eram outros estabelecimentos de ensino e foram transformados em campi dos 38 IF espalhados pelo Brasil. Foram consideradas as escolas em funcionamento, com matrículas e docentes de turmas, exceto as de Atendimento Complementar ou de Atendimento Educacional Especializado. Do banco de matrículas foram obtidos o número de matrículas no ensino médio integrado em cada estabelecimento, além da distribuição por série escolar, raça/cor, faixa etária e sexo dos alunos. Para o levantamento de dados de aprovação, reprovação e abandono em cursos de ensino médio integrado nos IF, foram consultados os Relatórios de Taxas de Rendimento, de 2007 a 2016, também do Instituto Nacional de Estudos e Pesquisas Anísio Teixeira. Para a análise comparativa entre as características da distribuição dos campi dos IF bem como dos estudantes de cursos de ensino médio integrado e a distribuição e a composição populacional brasileira foram utilizados dados da Pesquisa Nacional por Amostra de Domicílios (PNAD), do IBGE.

Considerando que o direito à educação se dá inicialmente pela expansão das oportunidades educativas para todos, foi realizada a análise do processo de expansão e interiorização dos IF. Observou-se que, entre 2007 e 2017, o número de campi aumentou $341 \%$. Esses campi se espalharam pelo Brasil fazendo com que a atuação da Rede Federal deixasse de ser predominantemente em regiões de grandes centros urbanos, o que favoreceu o acesso e a permanência de estudantes que moram no interior. 
Assim, em 2017, haviam 564 unidades distribuídas por 522 municípios nos 26 estados e no Distrito Federal, isto é, 9,4\% dos 5.570 municípios brasileiros tinham, pelo menos, um campus do IF instalado em seu território, atendendo também aos municípios circunvizinhos. Dos campi em atividade no ano de 2017, 90,2\% foram instalados fora das capitais dos estados e dos municípios que receberam campi, 35,8\% tinham população com menos de 50.000 habitantes segundo estimativas do IBGE.

Analisando a capilarização pelas regiões do Brasil, a maior expansão entre 2007 e 2017 se deu nas regiões Centro-Oeste (550\%), Norte (386\%) e Sul (382\%). Quanto aos números absolutos a Região Nordeste contava em 2017 com o maior número de campi (193). Na sequência vinha a Região Sudeste (132), Região Sul (106), Região Norte (68) e Região Centro-Oeste (65). Comparando a distribuição dos campi com a distribuição da população pelas regiões brasileiras, a proporção é diferente apenas entre a Região Nordeste e Sudeste, em que a segunda é mais populosa do que a primeira.

Outro dado levantado com relação à distribuição dos campi é que, nesta série histórica de 2007 e 2017, a expansão foi maior nas áreas urbanas (425\%) do que nas rurais (132\%). Percebe-se certa proporcionalidade com relação à distribuição da população pelo território brasileiro, pois os dados da Pesquisa Nacional por Amostra de Domicílios (PNAD) 2015 indicam que 84,7\% da população brasileira viviam naquele ano em áreas urbanas e 15,3\% dos brasileiros viviam em áreas rurais.

O passo seguinte foi analisar a oferta de matrículas em cursos de ensino médio integrado diante da variedade de cursos em níveis e modalidades diversas que os IF podem ofertar. Em 2007, as matrículas nas instituições que se transformariam em unidades dos IF representavam 19,7\% do total e, em 2017, passaram a representar 49,5\%. Esse aumento representa expansão na atuação dos IF no ensino médio. No entanto, mesmo em 2017 não foram alcançados os 50\% de matrículas determinados pela lei de criação dos IF. Os cursos subsequentes, isto é, aqueles destinados a oferecer educação profissional a quem já conclui a educação básica, também são considerados de nível médio. Porém, não elevam a escolaridade, o que não representa avanço no direito à educação.

Quanto à distribuição das matrículas em cursos de ensino médio integrado nos IF pelo território brasileiro, observou-se que a maior expansão se deu na Região Sul (1.455\%) e a menor na Região Norte (383\%). Considerando todo o território brasileiro, a expansão dessas matrículas, entre 2007 e 2017, foi de 613\%. A distribuição de matrículas por região brasileira, em números absolutos, segue a mesma ordem decrescente da distribuição de campi observada anteriormente. Assim, a Região Nordeste concentrava, em 2017, o maior número de matrículas (59.938), seguida das regiões Sudeste (37.137), Sul (26.876), Norte (19.981) e Centro-Oeste (17.994).

Em 2007, 57,8\% dos campi distribuídos pelo território brasileiro ofertavam cursos de ensino médio integrado. Em 2017 essa porcentagem aumentou para 83,5\%. Em áreas 
rurais houve a expansão de $360 \%$ nas matrículas em cursos de ensino médio integrado, enquanto em áreas urbanas houve uma expansão de 692\%.

Constata-se, portanto, a ampliação da oferta de vagas em cursos de ensino médio integrado pelos institutos federais, o que representa democratização do acesso a uma instituição da Rede Federal, que conta com estrutura física em geral melhor equipada e com a elevada formação de seus servidores. Embora não ofertem vagas suficientes para atender à demanda, é notável que o processo de expansão e de interiorização dos IF explicita uma política de ampliação de oportunidades educativas em todas os formatos de curso que ofertam e, mais especificamente, do direito à conclusão da educação básica tanto aos que moram no interior do País, quanto aos que vivem nos grandes centros urbanos, mas que disputavam pouquíssimas vagas em escolas da rede Federal.

Foram também levantados os dados sobre sexo, raça/cor e faixa etária dos alunos matriculados no ensino médio integrado. Com relação à renda, intenção inicial da pesquisa, não foi possível realizar o levantamento, porque o Censo Escolar não faz a coleta deste tipo de informação.

Observou-se que, até o ano de 2013, a maior parte das matrículas em cursos de ensino médio integrado era realizada pelo sexo masculino. Em 2014, porém, as matrículas do sexo feminino foram ampliadas em 19,7\% em relação ao total de matrículas de 2013, e as matrículas do sexo masculino diminuíram $1 \%$, fazendo com que mais pessoas do sexo feminino realizassem as matrículas no ensino médio integrado em comparação com o sexo masculino. Nos anos seguintes houve gradual diminuição na diferença no número de matrículas entre os sexos, chegando, em 2017, a uma equiparação em que 50,1\% das matrículas foram realizadas pelo sexo feminino e $49,9 \%$ pelo sexo masculino.

A análise das matrículas por raça/cor em cursos do ensino médio integrado foi prejudicada devido ao alto índice de matrículas em que esse dado não é declarado. Embora esse índice tenha diminuído na série histórica analisada (de 70,4\% em 2007 para 32,3 em 2017), o elevado número de matrículas que não dispõe dessa informação pode interferir na proporção de ocupação das vagas em todas as categorias referentes a esse critério, dificultando a compreensão do movimento delas nas matrículas. Então, nesta pesquisa levou-se em conta os dados apenas das matrículas em que houve indicação de raça/cor.

De 2007 a 2017, observou-se aumento na declaração de todas as raças/etnia. As de cor branca foram as que mais aumentaram: $2.162 \%$, seguidas das declarações de cor parda em $1.330 \%$, amarela em $784 \%$, preta em $771 \%$ e de indígena em $268 \%$. Há nas matrículas prevalência de declaração de brancos e pardos em todos os anos. Em 2017, 32,1\% das matrículas realizadas em cursos de ensino médio integrado foram realizadas por estudantes que se declararam brancos e 31,5\% pardos, prevalência também observada na composição da população brasileira em 2017: 43,6\% da população se declarou branca e 46,8\%, parda, segundo dados da Pesquisa Nacional por Amostra de Domicílios Contínua 2012-2017. 
Pode-se afirmar, na comparação entre a composição das matrículas e a composição da população por raça/cor, que os IF estão atendendo as populações conforme predominância nos grupos populacionais. Um importante mecanismo de ampliação de oportunidade educacional que deve ser lembrado é a Lei n⿳0 12.711/2012, a Lei de Cotas, que garante a reserva de vagas para pretos, pardos, indígenas, pessoas com deficiência, de baixa renda e estudantes de escolas públicas em instituições públicas federais.

Quanto à faixa etária dos estudantes matriculados nos cursos de ensino médio integrado, identificou-se que, em todos os anos, de 2007 a 2017, a maioria tinha de 14 a 18 anos. No entanto, em 2017 houve ampliação da porcentagem de matrículas de estudantes de 16, 17 e 18 anos. Esse dado pode revelar os efeitos das reprovações. No entanto, é importante destacar que houve aumento no número de campi que passaram a ofertar cursos de quatro anos de duração, o que também justifica o aumento no número de estudantes com 18 anos.

Pode-se afirmar que a expansão de IF se deu num processo intenso e de interiorização. O mesmo aconteceu com as matrículas nos cursos de ensino médio integrado neles realizadas. Constatou-se, portanto, a ampliação do direito à educação básica em termos de expansão das oportunidades educativas pelos IF. É preciso, pois, abordar ainda a qualidade do ensino ofertada já que para o direito à educação básica se efetivar é preciso que haja a conclusão do ensino médio. Embora a questão da qualidade, em se tratando de educação escolar, envolva diversas dimensões que vão do financiamento da educação no Brasil ao trabalho pedagógico realizado, neste trabalho a qualidade foi analisada apenas por meio dos dados de aprovação, reprovação e abandono, extraídos do Censo Escolar e publicados no Relatório de Taxas de Rendimento do Inep. Porém, não foi possível analisar os dados do ano de 2017, porque até o final do período da pesquisa não haviam sido divulgados.

Observou-se no ano de 2007 a menor porcentagem de aprovação total $(84,4 \%)$. Porém, nos anos seguintes, as porcentagens de aprovação pouco evoluíram, atingindo a maior porcentagem em 2014 (87\%). A reprovação diminuiu tendo maior percentual em 2007 (13,2\%) e o menor em 2016 (9,4\%). Quanto ao abandono, houve variação: a menor porcentagem ocorreu no ano de 2010 (2\%) e o maior em 2016 (5,5\%). Analisados por ano escolar, observa-se que, em geral, as maiores porcentagens de reprovação e abandono se dão no primeiro ano do ensino médio integrado. As aprovações aumentam, em geral, nos terceiros e quartos anos.

As médias percentuais de rendimento escolar revelam que a reprovação e o abandono são elevados nos cursos de ensino médio integrado nos IF e indicam que a qualidade no ensino remetida a estas instituições não se dá para o conjunto dos estudantes. O IF apresenta um excelente desempenho nas avaliações de larga escala, mas isso não significa qualidade de educação para todos. Isso implica estabelecimento de desigualdades significativas quanto à efetivação da apropriação dos conhecimentos entre os estudantes. 
Assim, para que o IF atue significativamente na ampliação do direito à educação básica, é preciso incorporar medidas de melhoria nos percentuais de aprovação e de redução do abandono a partir da análise dos fatores que interferem no êxito dos estudantes e da definição coletiva de estratégias, para que todos concluam o ensino médio com efetiva apropriação do conhecimento.

\section{Considerações finais}

No Brasil, os avanços no acesso à educação se deram a passos lentos como resultado da atuação do Estado e da constituição de uma sociedade desigual. A universalização da educação básica é algo ainda a ser conquistada não só na declaração do código legal, mas na efetivação do que já está declarado.

O ensino médio apresenta-se como um desafio, pois, além de carecer de sentido para muitos jovens, também é uma etapa que sofre a influência de diferentes interesses. Historicamente, as disputas se travam no embate entre a formação integral e a formação para as demandas do mercado, o que resulta em políticas que acabaram por atribuir a dualidade como característica do ensino médio no Brasil.

O ensino médio integrado, com sua proposta de educação integral, que assegura a apropriação dos conhecimentos básicos a todos, passa a ser uma alternativa de acesso e conclusão da educação básica que se mostra significativo para os jovens e visa superar a fragmentação da formação. Integrado a educação profissional, o ensino médio ofertado pelos IF surge como opção inclusiva e de qualidade para a população.

A pesquisa revela que os IF atuaram significativamente na ampliação do direito à educação básica, pois expandiram, interiorizaram e democratizaram o acesso ao ensino médio integrado. Isso proporcionou a ampliação do acesso aos jovens numa forma de oferta que eleva a escolaridade, integrando a formação ampla à formação profissional. No entanto, o próximo passo para ampliar esse direito é garantir a aprendizagem de todos os alunos, diminuindo, consequentemente, os números de reprovação e de abandono dos cursos de ensino médio integrado, o que se configura, ainda, como um desafio.

Com potencial de se consolidar como uma política que contribui para a emancipação das pessoas, para o avanço econômico, cultural e social e para a diminuição das desigualdades sociais, os IF precisariam ser assumidos como política de Estado, num processo de consolidação e avanço no importante papel de democratização do conhecimento. No entanto, o cenário em curso sinaliza em sentido oposto. A reforma do ensino médio, por meio da Lei 13.415/17, se apresenta com potencial impacto negativo sobre os institutos federais e sobre o ensino médio integrado. A oferta de percursos diferenciados, por meio da subdivisão da trajetória escolar em itinerários formativos, limita o acesso ao conhecimento de forma precoce e acaba por ferir o direito à formação comum, 
assegurada na identidade do ensino médio como educação básica. A isso se somam outros dois aspectos que retrocedem ao que vinha sendo construído. A ampliação da educação profissional integrada ao ensino médio (EMI) se fragiliza sobremaneira com a proposição na Lei 13.415/17, que, ao criar o itinerário da formação técnica e profissional, afirma a oferta concomitante em detrimento da integrada. Além disso, ao ser incluída na Lei que a formação técnica e profissional poderá ser feita por meio de parcerias, é de se indagar em que medida os IF irão atender ao disposto na Lei, ofertando as disciplinas da formação técnica e profissional em concomitância com as escolas das redes estaduais de ensino, que ofereceriam os componentes curriculares da formação científica básica, fragilizando, desse modo, os objetivos centrais dessas instituições e a obrigatoriedade do percentual de oferta destinado ao ensino médio integrado.

Recebido em: 12/11/2020 e Aprovado em: 18/12/2020

\section{Referências}

BRASIL. Constituição da República Federativa do Brasil. Brasília, 1988.

. Emenda Constitucional $n^{0} 59$, de 11 de novembro de 2009. Acrescenta $\S 3^{\circ}$ ao art. 76 do Ato das Disposições Constitucionais Transitórias para reduzir, anualmente, a partir do exercício de 2009, o percentual da Desvinculação das Receitas da União incidente sobre os recursos destinados à manutenção e desenvolvimento do ensino de que trata o art. 212 da Constituição Federal, dá nova redação aos incisos I e VII do art. 208, de forma a prever a obrigatoriedade do ensino de quatro a dezessete anos e ampliar a abrangência dos programas suplementares para todas as etapas da educação básica, e dá nova redação ao $\S 4^{\circ}$ do art. 211 e ao $\S 3^{\circ}$ do art. 212 e ao caput do art. 214, com a inserção neste dispositivo de inciso VI. Disponível em: http://www.planalto.gov.br/ccivil_03/constituicao/Emendas/Emc/emc59.htm. Acesso em: 04 mar. 2020.

Decreto $n^{0} 5.840$, de 13 de julho de 2006. Institui, no âmbito federal, o Programa Nacional de Integração da Educação Profissional com a Educação Básica na Modalidade de Educação de Jovens e Adultos - PROEJA, e dá outras providências. Disponível em: http://www.planalto.gov.br/ccivil_03/_ ato2004-2006/2006/decreto/d5840.htm. Acesso em: 04 mar. 2018

. Lei $\eta^{09} 9.394$, de 20 de dezembro de 1996. Estabelece as diretrizes e bases da educação nacional. Disponível em: http://www.planalto.gov.br/ccivil_03/leis/19394.htm. Acesso em: 04 mar. 2020.

. Lei n⿳⺈⿴囗十一 11.892, de 29 de dezembro de 2008. Institui a Rede Federal de Educação Profissional, Científica e Tecnológica, cria os Institutos Federais de Educação, Ciência e Tecnologia, e dá outras providências. Brasília: 2008. Disponível em: http://www.planalto.gov.br/ccivil_03/_ato2007-2010/2008/lei/111892.htm. Acesso em: 08 mar. 2020.

. Lei $n^{0} 12.711$, de 29 de agosto de 2012. Dispõe sobre o ingresso nas universidades federais e nas instituições federais de ensino técnico de nível médio e dá outras providências. Disponível em: http://www.planalto.gov.br/ccivil_03/_ato2011-2014/2012/lei/ 112711.htm. Acesso em: 09 mar. 2020. 
Lei 13.005, de 25 de junho de 2014. Aprova o Plano Nacional de Educação e dá outras providências. Brasília-DF, 26 jun. 2014. Disponível em: http://fne.mec.gov.br/images/doc/LeiPNE.pdf. Acesso em: 05 mar. 2020.

Ministério da Educação. Secretaria de Educação Profissional e Tecnológica. Instituto Federal de Educação, Ciência e Tecnologia um novo modelo em educação profissional e tecnológica: concepção e diretrizes. Brasília, 2010. Disponível em: http://portal.mec.gov.br/dmdocuments/livreto_institutos.pdf.

Acesso em: 05 mar. 2020.

CIAVATTA, Maria. Formação integrada: caminhos para a construção de uma escola para os que vivem do trabalho. In: PARANÁ. Secretaria de Estado da Educação. Superintendência da Educação. Departamento de Educação e trabalho. O Ensino Médio Integrado à Educação profissional: conceitos e construções a partir da implantação na Rede Estadual do Paraná. Curitiba: SEED, 2008, p.77-90.

GRAMSCI, Antonio. Os intelectuais. O princípio educativo. In: . Cadernos do Cárcere. Tradução de Carlos Nelson Coutinho. V. 2. 2. ed. Rio de Janeiro: Civilização Brasileira, 2001.

IBGE. Pesquisa Nacional por Amostra de Domicílios Contínua 2012-2017: características gerais dos moradores. Disponível em: https://www.ibge.gov.br/estatisticas-novoportal/sociais/populacao/17270-pnadcontinua. html?edicao=18264\&t=downloads. Acesso em: 09 mar. 2020.

Diretoria de Pesquisas - DPE - Coordenação de População e Indicadores Sociais - COPIS. Estimativas da população residente nos municípios brasileiros com data de referência em $1^{1}$ de julho de 2017. Disponível em: ftp://ftp.ibge.gov.br/Estimativas_de_Populacao/Estimativas_2017/estimativa_dou_2 017.pdf. Acesso em: 08 jul. 2020.

INEP. Censo Escolar da Educação Básica 2007-2017. Brasília: INEP, 2008-2018.

Relatório de Taxas de Rendimento 2007-2016. Brasília: INEP, 2008-2017.

Relatório do 3oㅡ Ciclo de Monitoramento do Plano Nacional de Educação. Brasília, INEP, 2020.

Disponível em: http://www.educacao.pr.gov.br/sites/default/arquivos_restritos/files/documento/2020-08/ pme_relatorio_3_ciclo_monitolramento_metas_pne_2020.pdf Acesso em: 20 out. 2020

MOURA, Dante Henrique; LIMA FILHO, Domingos Leite; SILVA, Mônica Ribeiro da. Politecnia e formação integrada: confrontos conceituais, projetos políticos e contradições históricas da educação brasileira. Revista Brasileira de Educação. Rio de Janeiro, v. 20, n. 63, pp.1057-1080, 2015.

SILVA, Monica Ribeiro. Ampliação da obrigatoriedade escolar no Brasil: o que aconteceu com o Ensino médio? Ensaio: avaliação e políticas públicas em educação, Rio de Janeiro, v. 28, n. 107, p. 274-291, abr.jjun. 2020. 